\title{
The Quantity and Quality of Language Practice in Typical Interactive Pair/Group Tasks
}

\section{Laura Collins $\mathcal{E}$ Joanna White}

This article reports on a study examining the language practice opportunities that occurred during a range of paired and small group interactive tasks in an intensive English as a Second Language (ESL) class of francophone Grade 6 students. The analysis focussed on the opportunities the tasks provided for the use of two complex and challenging forms (the simple past and the possessive determiners his/her) by these learners. We examined both the quantity and the quality of the contexts for the two target forms within the tasks, and whether particular task types or task features were associated with more or richer practice for the forms.

Cet article fait rapport d'une étude qui examine les occasions de pratiquer la langue qui se sont présentées pendant diverses tâches interactives accomplies en petits groupes dans un cours intensif d'anglais langue seconde avec des étudiants francophones en 6e année. L'analyse a porté sur les occasions présentées aux apprenant pendant les tâches pour employer deux formes complexes et difficiles (le passé simple et les déterminants possessifs « his » et " hers »). Nous avons examiné tant la quantité que la qualité des contextes pour les deux formes ciblées, ainsi que les différentes sortes de tâches pour déterminer si elles étaient liées à un emploi plus riche ou fréquent des formes.

Tasks have been defined in a number of different ways in the second language pedagogy and research literature (for a review, see Samuda \& Bygate, 2008). Some scholars, such as Scrivener (2011), the author of an ESL pedagogy textbook that is widely used in teacher education programs, take a very broad view, considering tasks and activities to be interchangeable terms.

The basic building block of a lesson is the activity or task. We'll define this fairly broadly as "something that learners do that involves them using or working with language to achieve some specific outcome." The outcome may reflect a "real world" outcome or it may be purely a "for-the-purposes-of-learning" outcome. (Scrivener, 2011, p. 37)

Scrivener includes in his definition drill-like activities, such as repeating sentences after the teacher to improve pronunciation (p. 38).

Others distinguish between tasks and activities, seeing the former as a subset of the latter (e.g., Philp, Adams, \& Iwashita, 2014; Samuda \& Bygate, 2008). Samuda and Bygate (2008) describe a task as a holistic activity in which learners make use of their knowledge of various subareas of language (vocab- 
ulary, phonology, grammar, discourse structures) simultaneously, to achieve a meaningful outcome. Ellis refined this definition, specifying four key criteria that a language teaching activity must satisfy to be considered a task. They are (a) a primary focus on meaning; (b) a gap to be filled (convey information, express an opinion, infer meaning); (c) a reliance by the learners on their own linguistic and nonlinguistic resources to complete the task (although the task input may provide some language support); (d) a clearly defined outcome other than the use of language-the language serves as the means to achieve the outcome, not as the end. Thus learners are not primarily concerned with correct use of language but with achieving the goal stipulated by the task (Ellis, 2009, p. 223; Ellis \& Shintani, 2014, pp. 135-136).

According to this definition, grammar exercises such as the drills described by Scrivener (2011) do not satisfy either the first criterion, because the learners know they are practicing grammar, or the fourth criterion, because the intended outcome is the use of correct language (Ellis, 2009). This is not to say that tasks cannot have a linguistic focus; indeed, Ellis (2009) notes that tasks can be either focused or unfocused so long as they satisfy the four criteria listed above. "Focused tasks are designed to provide opportunities for communicating using some specific linguistic feature (typically a grammatical structure)" (Ellis, 2009, p. 223) and may even predispose learners to choose them.

The language teaching activities recorded and analyzed for this study meet these criteria. That is, we have targeted oral interaction in pairs and small groups in which the learners' primary focus is on meaning to exchange information and opinions, solve problems, or plan events. Learners rely largely on their own resources to complete the task, which has a clearly defined nonlinguistic outcome but may also involve a linguistic challenge and some language support that potentially pushes language learning.

\section{Oral Interaction and Tasks}

The interest in the effects of oral interaction on second language acquisition has been the focus of considerable research since Long (1983) first articulated his Interaction Hypothesis (updated in Long, 1996), which attributed a key role to the types of conversational modifications that occur when a second language speaker is striving to both understand and be understood. This interest has since been extended to an examination of the impact of different task types and task features on acquisition (e.g., Robinson, 2001; Skehan \& Foster, 1997, 2001), resulting in a sufficient number of studies to permit a meta-analysis of the impact of task features on the acquisition of grammar and lexis (Keck, Iberri-Shea, Tracy-Ventura, \& Wa-Mbaleka, 2006). Keck et al. (2006) conclude, however, that the pedagogical implications of their analysis of the 14 studies $^{1}$ reviewed are limited by at least three factors. The first is that most of the research has focused on a restricted range of task 
types (just two of the six potential types in the framework used: information gap and jigsaw tasks). Whether the findings hold true for other task types and indeed whether these two tasks are representative of tasks learners typically do in actual language classrooms remain open questions. A related factor is that the overwhelming majority of the research has been conducted in lab settings with tasks chosen by researchers. In addition, much of the research has not focused on learner-learner interaction in dyads or small groups; typically it has involved a "native speaker" or proficient speaker of the target language interacting with an L2 learner. Indeed, only 3 of the 14 studies involved learners interacting with each other. Two meta-analyses of feedback during oral interaction reported similar findings: Russell and Spada (2006) found no studies of learner-learner interaction; Mackey and Goo (2007) found only two. ${ }^{2}$ Keck et al. further report that the use of different linguistic features that arise during oral interaction has received little attention; studies are often designed with a target feature in mind. Finally, most of the research has been conducted with adult learners at language institutes or in university settings.

Thus we know very little about the use of different linguistic features during oral interaction in typical pair and small group work tasks performed in ESL classrooms, and even less about these issues among children and adolescents learning a second language in school-based language programs. Of particular interest for the current study was the degree to which typical tasks provide contexts for learners to use complex or challenging forms during oral interaction. Swain $(1993,1995)$ has argued that a crucial component of language production is "pushed" output-that is, opportunities for language use that allow learners to notice gaps in their knowledge and test hypotheses about target language forms. Clearly, however, for learners to engage in the types of consciousness-raising, reflection, and utterance repairs that Swain has identified as key for acquisition, the tasks they are doing need to create contexts for challenging or partially acquired forms to occur. The goal of our study was to examine the contexts created during oral interaction for two such features of English: the simple past tense and the possessive determiners (PDs) his and her.

\section{Simple Past and Possessive Determiners (PDs) his/her}

The choice of the two language targets was motivated by a number of factors. Both the simple past and PDs are important for communication: the past allows speakers to move beyond the "here and now" to situate events in time ${ }^{3}$; PDs facilitate descriptions of people and their relationships to each other. They also represent two different aspects of grammar, morphology for the simple past and syntax (or morphosyntax) for the PDs. They are thus examples of complex forms that considerably expand a learner's communicative and grammatical competence in the L2. In addition, the acquisition 
challenges and the input profiles of the two features have been documented in previous research, including research involving francophone ESL learners, the target population of our study (e.g., Collins, Trofimovich, White, Cardoso, \& Horst, 2009; Collins, White, Trofimovich, Cardoso, \& Horst, 2012).

The irregular/regular distinction, perceptual salience, and verb type constitute three of the acquisition challenges that have been observed in the use of the simple past tense. Control over the feature requires knowledge of both the irregular and regular forms, but systematic use of the irregular past (did, said, went) tends to occur before productive use of the regular past (Lee, 2001; Rohde, 1996). At least some of the difficulty derives from the lack of perceptual salience of the regular form of the simple past (Bell, Trofimovich, \& Collins, in press; McDonald \& Roussel, 2010; see also Bayley, 1996; Goad, White, \& Steele, 2003; Wolfram, 1985). In addition, learners initially make much more frequent use of the simple past with the class of verbs known as telics (finished, made something), which are bounded events with inherent end points. Expansion of the system involves productive use of the form with atelics, that is, activities (danced, listened to music) that have arbitrary end points and states (felt, heard, wanted) (Bardovi-Harlig, 2000; Collins, 2002, 2004).

As for PDs, the challenge involves understanding the link between the possessor and the possessed entity. In English, the gender of the third person singular possessive determiner agrees with the natural gender of the possessor. Thus, in the first example below we assume that both the shirt and the mother belong to Bill, whereas in the second example, both the hat and mother belong to Mary.

1. Bill is wearing his new shirt. He and Mary are talking with his mother.

2. Mary is wearing her new hat. She and Bill are talking with her mother.

In some languages, including the L1 French of our participants, the equivalents for his and her depend on whether the noun possessed (object or person) has masculine or feminine grammatical gender. Thus the French equivalent of shirt and mother in the examples above would both take the feminine $s a$ (sa chemise; sa mère), whereas hat would take the masculine son (son chapeau). In example 1, a learner who incorrectly applied the French rule to English might say that Bill and Mary are talking with her mother. We see this incorrect assumption most clearly in kin-different contexts, that is, when the natural gender of the possessor (in this example, masculine Bill) is different from the natural gender of the possessed noun (in this case, mother). Learners progress through a sequence of stages as they gradually differentiate between his and her, becoming more accurate with the crucial kin-different contexts in later stages. This has been documented in the oral production of young francophone, Brazilian Portuguese, Spanish, and Catalan learners of English in classroom settings (White, 1998; White \& Cardoso, 2012; White, Munoz, \& 
Collins, 2007). Although the descriptive rule is easy to state (the gender of the PD agrees with that of the possessor), processing the form is difficult (White \& Ranta, 2002), and errors in kin-different contexts often persist long after PDs are produced correctly with other collocates (e.g., inanimate or abstract nouns and body parts). For this reason, learners need to engage in tasks that provide opportunities to practice using these more challenging forms.

There was a further motivation for the study. Previous research, focused on the instructional input that the participants of our study typically receive, established that both simple past and PDs are infrequent, lack salience, and occur in restricted semantic contexts. That is, there is little exposure to regular (as opposed to irregular) verbs or to verbs in stative (e.g., feel, hear, want) or activity (dance, listen to music, sleep) contexts. Similarly, the PDs rarely occur in the crucial kin-different contexts illustrated above (Collins et al., 2009; Collins et al., 2012). Thus the overall quantity and quality of exposure in the language classrooms (the primary source of input for these children, who live in predominantly francophone environments with few opportunities to use English) is less than optimal for the acquisition of the forms. Left unanswered, however, was the question of whether output opportunities are similarly impoverished when learners engage in the types of oral interaction they typically do in their language classes.

\section{Goals and Research Questions}

One goal of the research was to document the degree to which typical oral interaction tasks in genuine classrooms (as opposed to the laboratory-based contexts typical of much of the previous research) afforded young francophone learners opportunities to use two challenging forms, the simple past and the possessive determiners his/her. The second goal was to examine characteristics of the tasks that provided better opportunities for producing the forms, in both frequency of occurrence and quality of learning contexts. Quality opportunities were defined in terms of the lexical characteristics of the nouns and verbs associated with the target grammar.

There were three sets of research questions. The first set of two addressed the quantity of opportunities to use the simple past and PDs, the second set of two the quality of opportunities to use the target forms, and the final two the task types and features offering superior practice contexts.

\section{Research Questions}

Within a corpus of typical oral interaction tasks:

1. What percentage of the finite verb phrase contexts focuses on prior events, requiring the use of simple past?

2. What percentage of the PD contexts focuses on descriptions of people and their relationships with each other, requiring the use of his/her? 
3. What is the distribution of lexical verbs (telics: I won the game; activities: I played tennis; states: I felt nervous) in the simple past contexts? High quality contexts would be those that included reference to the less prototypical atelic situations, states, and activities.

4. What is the distribution of collocated noun types (inanimate: He lost his sweatshirt; animate kin same: She called her mother; animate kin different: He called his mother; body parts: She hurt her hand) in the his/her PD contexts? High quality contexts would be those that included reference to animate kin different relationships.

5. What task types or features of tasks are associated with greater opportunities to use the target forms? (No predetermined task categories were entertained; the analysis was to be data driven, interpreted where relevant with respect to previous research on tasks in other contexts).

6. What task types or features of tasks are associated with higher quality contexts for using the target forms?

\section{Methodology}

\section{Context}

The study was carried out in an intact Grade 6 intensive ESL class in a Frenchdominant region of Quebec, outside Montreal. The intensive program was open to every Grade 6 child (age 11-12) in the school who was not in danger of failing French or math and/or who had not been diagnosed with behavioural problems. These criteria resulted in two intensive ESL groups and one "regular" group that studied ESL nonintensively (two hours a week); our study involved one of the intensive groups. The primary ESL program in Quebec is communicatively oriented, with an emphasis on oral interaction (speaking and listening), and pair/small group activities are frequent from the early grades. Data were collected in the fourth month of a five-month program in which students had 4-5 hours of English every day. The focus here is on one school; it is part of a larger study of three intensive classes in three different schools. (For more information on intensive ESL in Quebec, including how it differs from content-based immersion programs, see Collins, Halter, Lightbown, \& Spada, 1999; Collins \& White, 2011; Lightbown, 2012.)

\section{Participants}

\section{Teacher}

The teacher, a French-English bilingual, has taught intensive ESL for over 20 years. She has TESL training and extensive experience with cooperative learning. Following the Quebec Ministry of Education ESL program, she prioritizes speaking and collaboration. She focuses on meaning more than form, even within tasks that could have a form focus. She was not aware of the language targets addressed in this study. 


\section{Students}

The 29 Francophone students in the group we studied had completed their academic subjects intensively in L1 French during the first five months of Grade 6 (September-January) and had their intensive ESL experience in the final five months of the year (February-June). By the fourth month of intensive English, the students could be described as low-intermediates. That is, although their oral language was not always accurate, they were able to express themselves on a wide variety of everyday topics and could follow age-appropriate television programs. They were motivated and enthusiastic about English and communicatively confident.

\section{Data Collection and Corpus}

The data were collected once a week over a period of four weeks. During each of our visits, which lasted about 60 minutes, the students were engaged in several pair- or group-work tasks that the teacher described as "typical" for the fourth month of the intensive program. While students were familiar with some of the task types (e.g., interviews), they had not yet done any of the 11 that were recorded for this study. Prior to the actual data collection, researchers visited the class, introduced students to the study, familiarized them with the audio equipment, and did a few trial recordings. During the data collection, all the pair- and group-work interactions were audio-recorded, with one digital audio recorder per pair or group of 3 students doing the same task at the same time. The 26 hours of oral interaction were then transcribed and verified, which yielded a corpus of 93,417 words.

Additional sources of data include all the task materials used by the students, field notes made during the recording of each task by two research assistants, and a semistructured interview with the teacher after all the tasks had been transcribed.

Table 1 provides a description of the tasks, the number of participants for each, and the average time each pair/group took to complete the task. The tasks consisted of interviews, games, descriptions, comparisons, giving and following directions, discussions, consensus, predictions, and writing tongue twisters. Note that none resemble the picture differences, dictogloss, or jigsaw tasks that have figured in previous research on tasks and interaction (Keck et al., 2006; see also Mackey, 1999; Pica, 1987; Pica, Kang, \& Sauro, 2006; Swain \& Lapkin, 2000, 2001).

Task input included worksheets with model sentences or suggested language; scripted text exchanged as clues to solve puzzles; and resources available in the classroom such as workbooks, word banks, dictionaries, and wall posters. The teacher gave clear instructions and usually modeled the task, sometimes drawing learners' attention to language that would be useful for completing the task. There was always a task outcome, such as the solution to a puzzle, a paragraph to use in a guessing game, a tongue twister created 
through collaboration, a consensus, or a prediction. Some of the tasks were focused, in which communication involved the use of a specific linguistic feature (e.g., question forms for interviews, clothing vocabulary for the guessing game, words that begin with the same letter in the tongue twister story), but the overall purpose of all tasks, for the students and the teacher, as well, was to exchange meaning.

Table 1

Pair/Group Tasks

\begin{tabular}{lrr}
\hline Types of task & $\begin{array}{r}\text { \# pairs/ } \\
\text { groups }\end{array}$ & $\begin{array}{r}\text { Mean length } \\
\text { (minutes) }\end{array}$ \\
\hline Closed interview about weekend (Did you ...) & 15 & 4 \\
Open interview about weekend (Where/what, etc. ...) & 15 & 3 \\
Clothing description (guessing game) & 14 & 20 \\
Interview about pretend past activities & 14 & 6 \\
Comparisons of favourite objects and activities & 14 & 14 \\
Creating tongue twisters & 13 & 34 \\
Directions around the class & 10 & 12 \\
Directions for a taxi around the town (game) & 14 & 8 \\
Directions around a zoo (game) & 10 & 14 \\
Discussion of items to take on an expedition (consensus) & 10 & 10 \\
Predicting classmates' future & 9 & 3 \\
\hline
\end{tabular}

Most of the tasks were done in pairs, with students sometimes switching partners from one task to the next. Note that the length of the oral interaction varied, ranging from a mean per pair/group of 3-4 minutes for interviews and predictions to 34 minutes for the creation of the tongue twister.

\section{Analyses and Findings}

This section is divided into two parts. In the first part, we report on the analyses of the contexts for the simple past and the PDs across the entire corpus, independent of task type. These analyses address the first four research questions, that is, the quantity and the quality of the contexts that provided opportunities to use the target forms. The second part focuses on the task types and task features that provided greater opportunities and higher quality contexts for using the simple past and PDs, thereby addressing the final two research questions.

\section{Distribution of Contexts for Simple Past and Possessive Determiners his/her}

The first step consisted of identifying all the contexts for finite verb forms and possessive determiners in the corpus. This allowed us to calculate the frequency of the contexts for simple past relative to other finite verbs (pres- 
ent, present perfect, futures, etc.), and of his/her contexts relative to the other possessive determiners (my, your, its, our, their). It is important to emphasize that the accuracy of students' use of the forms was not considered; the emphasis was on whether the oral interaction provided contexts for the forms. The obligatory contexts for past were determined collaboratively by a team of three researchers.

Of the 11,392 contexts for finite verb forms in the corpus, 3,359 (29\%) involved the simple past. The simple present accounted for the largest proportion of finite verb contexts, with $6,495(57 \%)$. The remaining $14 \%$ of the contexts were spread across a variety of forms, including present progressive, future, and modals. Within the simple past contexts, however, only 1,232 $(11 \%)$ involved situations where the lexical verb would be conjugated, that is, contexts other than asking yes/no questions (Did you/Were you ...); responding with short answers (Yes, I did/No, I didn't); or using negatives (I didn't go ...). Furthermore, when the situation called for the past tense form on the lexical verb, very few provided opportunities to consolidate knowledge of the regular past $(28 \%)$, as the overwhelming majority of the exchanges involved the use of irregular verbs $(72 \%)$.

Of the 658 contexts for possessive determiners in the corpus, there was an equal distribution among his/her (209; 32\%), my (225; 34\%), and your (224; $34 \%)^{4}$

\section{Quality of Contexts for Simple Past and Possessive Determiners his/her}

To determine the quality of the contexts for the target forms, we looked at the lexical aspect of the verbs used in the simple past contexts (statives, activities, and telics), and at the nouns collocated with the his/her PDs (inanimate/ abstract; animate kin-same; animate kin-different; body parts).

The coding of lexical aspect was done by two trained raters, both graduate students in applied linguistics with a strong background in linguistics. They followed a set of operational tests for determining lexical aspect that we have used in our previous research (Collins et al., 2009; Collins et al., 2012). To verify coding, each rater independently coded $20 \%$ of each other's files and met to discuss and resolve any discrepancies. The interrater reliability rate, calculated as the percentage agreement for all coded contexts, was $96 \%$.

The findings are displayed in Table 2. The token analysis, which looked at all instances of simple past verbs used in the corpus, revealed that most of the contexts involved telic verbs, with stative contexts the least frequent. The type analysis, which looked at each unique occurrence of a verb in the corpus, yielded a more balanced distribution, with equal contexts for activities and telics among the 98 verb types. Most of the verbs (88\%) were among the 1,000 most frequent words in the English language, as determined by a VocabProfile analysis using the Compleat Lexical Tutor (Cobb, 2000). The three most frequently used verbs were all irregulars: go (182), say (142), and be (112). The most frequent regular verb was play (68), followed by walk (47) and turn (44). 
Table 2

Lexical Aspect of Simple Past Verbs

\begin{tabular}{lrrrr}
\hline Context & \multicolumn{2}{c}{ Tokens } & \multicolumn{2}{c}{ Types } \\
\hline States & 210 & $17 \%$ & 12 & $12 \%$ \\
Activities & 391 & $31 \%$ & 43 & $44 \%$ \\
Telics & 661 & $52 \%$ & 43 & $44 \%$ \\
Total & 1,262 & & 98 & \\
\hline
\end{tabular}

Thus, although the tasks provided more repeated practice with telic verbs (the token results), there were balanced opportunities to use the simple past with both activities and telics (the type results). The type results also show opportunities for students to use statives other than just be, further demonstrating the quality of the practice the oral interaction tasks provided. ${ }^{5}$

The coding of the nouns collocated with the PDs was done by two other graduate students in applied linguistics. They classified the noun collocate for each instance of his and her in the transcripts according to the following categories: inanimate/abstract (his sweater, her turn), animate singular (her friend), animate plural (her friends), body part (his feet), animate kin-same (her mother), animate kin-different (her father), kin unclear (his friend, her parents), and unclear other. The target PD (the intended or correct form for the context) is the focus of the analysis and determined the categorization of the PD clause. The coders analyzed a portion of the transcripts together and developed a set of PD data analysis guidelines. Then they divided the transcripts, coded separately, and finally compared their findings. They resolved any differences in categorization when the context was clear and consulted about ambiguous PD contexts. For example, when a speaker did not finish his or her thought and the noun collocate was not named, the raters were usually able to infer it from the wider context. If not, the PD was coded as unclear. This occurred in 5 out of $168(3 \%)$ of the contexts for his and her.

The findings are displayed in Table 3. Inanimate/abstract and body part contexts, in equal numbers, account for all but one of the PD contexts (78 and 74 , respectively). There was one context for kin-same, and not a single one for kin-different.

Table 3

Semantic Contexts for his/her

\begin{tabular}{llrr}
\hline Context & Example & \multicolumn{2}{c}{ Tokens } \\
\hline Inanimate/abstract & his coat; her name & 78 & $52 \%$ \\
Animate kin-same & his father; her mother & 1 & $<1 \%$ \\
Animate kin-different & his mother; her father & 0 & $0 \%$ \\
Body parts & his hand; her arm & 74 & $48 \%$ \\
\hline
\end{tabular}




\section{Summary}

Overall, the profile for simple past contexts is richer than for his/her contexts. Although the simple past, especially the regular past, is infrequent in comparison with other finite verb phrases in the corpus, when it does occur, there are contexts for less prototypical verbs, including statives other than just $b e$. The contexts for his/her are frequent, relative to other PD forms in the paradigm, but the quality of the contexts is less than optimal as there is a total absence of contexts that drive interlanguage development toward mastery of the system (the kin-different collocated nouns).

\section{Distribution of Past and PD Contexts by Task}

The final set of analyses looks at the frequency and the quality of occurrence of the target forms by task, and the task features associated with higher frequency and superior quality.

To be able to compare across tasks of different lengths, we considered the total number of target feature contexts (his/her or simple past) created across all of the groups/pairs within each task, and the total amount of time in minutes spent on each task. The total time was divided by the contexts for the forms, yielding a metric that allows us to speak of frequency of the feature across minutes of interaction. Although this is a less fine-grained metric than, for example, a count per number of words used (e.g., Storch \& Aldosari, 2013; Williams, 2001), it is more meaningful for pedagogical implications to consider features of interaction within task time (see Pinter, 2007).

Table 4 displays the findings for PDs by task and time. In over half of the tasks (6 of 11) there were no contexts at all for PDs. The overwhelming

Table 4

Frequency of PD Contexts by Task

\begin{tabular}{lrrrr}
\hline & & $\begin{array}{r}\text { Total time } \\
\text { for all } \\
\text { groups } \\
\text { Task }\end{array}$ & $\begin{array}{r}\text { PD } \\
\text { frequency } \\
\text { (one } \\
\text { (is min) }\end{array}$ & $\begin{array}{r}\text { \# Groups } \\
\text { every..) }\end{array}$ \\
\hline Closed interview about weekend & 0 & 0 & 57 & NA \\
Cpen interview about weekend & 11 & $6 / 15$ & 45 & 4 min \\
Clothing description & 130 & $14 / 14$ & 290 & 2 min \\
Interview about pretended past activities & 0 & 0 & 77 & NA \\
Comparisons of favourite objects and & 4 & $2 / 14$ & 192 & 48 min \\
activities & & & & \\
Creating tongue twisters & 24 & $9 / 13$ & 413 & 17 min \\
Directions around the class & 0 & 0 & 117 & NA \\
Directions for a taxi around the town & 0 & 0 & 117 & NA \\
Directions around a zoo & 0 & 0 & 144 & NA \\
Discussion of items for an expedition & 1 & 1 & 100 & 100 min \\
Predicting classmates' future & 0 & 0 & 28 & NA \\
\hline
\end{tabular}


majority of the his/her contexts occurred within a single task, the clothing description game, and this was also the task in which the PDs occurred with the greatest frequency. Furthermore, in this task the focus is restricted to inanimate (e.g., his sweater, her bag) and body-part nouns (e.g., her feet), with 58 and 68 occurrences respectively, thus providing no practice with the more challenging animate categories. ${ }^{6}$ As there were no contexts for kin-different nouns in the corpus, no analyses for the tasks providing higher quality contexts could be considered.

Table 5 displays the findings for simple past by task and time. Although the contexts for past overall in the corpus were not frequent, they occurred in every task, unlike the PDs. They also occurred across a range of pairs/ groups for any given task (see Column 3). In three of the tasks (interviews about real and pretend weekend activities and the zoo game), more than one past context per minute was produced. Note that the time metric reveals that the greater concentration of past was not due to the overall length of the task; indeed, the weekend interview was one of the shortest tasks, yet it resulted in a high concentration of past contexts. There was also a considerable number of opportunities for past created by some of the pairs/groups in the collaborative construction of their tongue twisters. Although not every pair/group chose to situate their tongue twister in the past, those who did got substantial practice with past because of the repetitive nature of the task.

Table 5

Frequency of Past Contexts by Task

\begin{tabular}{lrrrr}
\hline Task & $\begin{array}{r}\text { Past } \\
\text { contexts }\end{array}$ & $\begin{array}{r}\text { \# Groups } \\
\text { contributing }\end{array}$ & $\begin{array}{r}\text { Total time } \\
\text { all groups } \\
\text { (in min) }\end{array}$ & $\begin{array}{r}\text { Past } \\
\text { (one every..) }\end{array}$ \\
\hline Closed interview about weekend & 17 & $15 / 15$ & 57 & $3 \mathrm{~min}$ \\
Open interview about weekend & 199 & $15 / 15$ & 45 & $<1 \mathrm{~min}$ \\
Clothing description & 25 & $10 / 14$ & 290 & $11 \mathrm{~min}$ \\
Interview about pretend past activities & 247 & $14 / 14$ & 77 & $<1 \mathrm{~min}$ \\
Comparisons of favourite objects & 72 & $11 / 14$ & 192 & $3 \mathrm{~min}$ \\
Creating tongue twisters & 154 & $13 / 14$ & 413 & $3 \mathrm{~min}$ \\
Directions around the class & 36 & $7 / 13$ & 117 & $3 \mathrm{~min}$ \\
Directions for a taxi around the town & 23 & $12 / 14$ & 117 & $5 \mathrm{~min}$ \\
Directions around a zoo & 437 & $10 / 14$ & 144 & $<1 \mathrm{~min}$ \\
Discussion of items for an expedition & 39 & $9 / 10$ & 100 & $2.5 \mathrm{~min}$ \\
Predicting classmates' future & 13 & $6 / 9$ & 28 & $2 \mathrm{~min}$ \\
\hline
\end{tabular}

For the quality of the simple past contexts in these four tasks (real and pretend events interviews, zoo game, tongue twister creation), we looked for cases where students were generating situations requiring verb types that included regulars and atelics (statives and activities). Table 6 shows that all four tasks generated contexts for students to use a considerable range of atelic 
types. In addition, there were opportunities to use almost as many regular past as irregular past types in the Zoo Game. The Tongue Twister task also resulted in a greater proportion of regular past types (38\%) than was seen across the corpus as a whole $(28 \%)$.

\section{Table 6}

Simple Past Contexts by Task Types:

Distribution of Lexical Aspect and Regular/Irregular Verb Types

\begin{tabular}{lrrrrrrr}
\hline Task & States & $\begin{array}{r}\text { Activ- } \\
\text { ities }\end{array}$ & Telics & Total & Regular & regular & Total \\
\hline Interview: real events & & & & & & & \\
$\quad$ Proportion & $9 \%$ & $56 \%$ & $35 \%$ & $100 \%$ & $31 \%$ & $69 \%$ & $100 \%$ \\
$\quad$ \# Raw types & 3 & 19 & 12 & 34 & 10 & 22 & 32 \\
$\quad$ Interview: pretend events & & & & & & & \\
$\quad \begin{array}{l}\text { Proportion } \\
\quad \text { \# Raw types }\end{array}$ & $11 \%$ & $42 \%$ & $47 \%$ & $100 \%$ & $26 \%$ & $74 \%$ & $100 \%$ \\
$\quad$ Zoo Game & 2 & 8 & 9 & 19 & 5 & 14 & 19 \\
$\quad$ Proportion & $21 \%$ & $27 \%$ & $52 \%$ & $100 \%$ & $46 \%$ & $52 \%$ & $100 \%$ \\
$\quad$ \# Raw types & 7 & 9 & 17 & 33 & 15 & 16 & 31 \\
$\quad$ Tongue Twister & & & & & & & \\
$\quad$ Proportion & $15 \%$ & $41 \%$ & $44 \%$ & $100 \%$ & $38 \%$ & $63 \%$ & $100 \%$ \\
$\quad$ \# Raw types & 6 & 17 & 18 & 41 & 15 & 25 & 40 \\
\hline
\end{tabular}

Note. The same verb in a different context can change lexical aspect (e.g., walk in the park is an activity, but walk to the store is telic). Thus the lexical type totals are sometimes greater than the verb totals for regular and irregular verbs.

\section{Task Features and Simple Past Contexts}

In examining the task features that resulted in frequent and quality simple past opportunities, two emerged as key. One was repetition inherent to the interaction created by the task. The other was structured content, in terms of language support or models for the oral exchanges.

In the weekend interview, for example, students took turns making a simple statement about an activity that they had done, for which their partners then needed to obtain more details. Sample questions were provided, but the students were free to ask for any information they were interested in knowing. The goal of the task was to learn about their classmates' weekend, information that was subsequently discussed with the whole class. Note that students did not always use the past accurately, but our interest was in whether the task created contexts where it could be used. Below is an excerpt from one pair's interaction.

Weekend Interview Excerpt 1

Charles:

Paul:

Charles:

Paul:
And I went to the movie theatre.

What- what movie did you watch?

I watch "Avengers."

Um why did you go at the theatre? 
Charles:

Because uh my uh my uncle want to see the movie.

Paul:

Charles:

It is good?

Yes, it was. Uh Sunday, I went to the park.

The Zoo Game was a problem-solving task. Each group had a map of a zoo with the animals identified and a set of clues involving the route two children took during their day at the zoo, in which several unexpected events occurred. Students took turns reading the clues aloud while the other group members traced the route on the map. The goal of the task was to determine which animal the children did not see by the end of their visit to the zoo. Not only did every clue provide varied and repeated contexts for the simple past (including at least one regular past per clue), ${ }^{7}$ there was also considerable repetition of the past forms as students asked for clarification or confirmed their understanding of the information. Below is an excerpt from one group's oral interaction; the text in caps is the clue being read aloud.

Zoo Game Excerpt 2

Daniel:

Then AT THE ZEBRA CORRAL THEY TURN EAST. THEY, THEY WALK PAST THE ZEBRAS, THEN WENT NORTH TO THE ELEPHANTS.

Melanie: Yes, I know....

Daniel: THEY WANTED SOME POPCORN, SO THEY WALKED EAST TO THE POPCORN STAND.

Melanie:

Maude:

Melanie:

Where is popcorn stand?

Daniel:

There is oh popcorn

Okay.

WHEN THEY GO uh THEN AMY REALIZED THAT SHE HAD LOST HER PURSE, THEY WENT BACK WEST TO ANTEATER AND THEN SOUTH ZEBRAS.

Melanie: $\quad$ Can you repeat please? And don't uh uh uh cause I don't understand. Don't make this.

Daniel: $\quad$ THEN AMY REALIZED THAT SHE LOST HER PURSE, SO THEY WENT BACK WEST TO THEN ANTEA- ANTHEATER...

Paul:

Anteater.

Past forms in the cues were not always read or paraphrased accurately, but overall there was more accurate suppliance of past than in the interview tasks where students had to generate the forms themselves. In addition, the scripted language of the clues included a wider range of regular verbs than the students tended to use in their own exchanges.

As we can see in the next excerpt from a different group, even students who were not reading the text sometimes repeated the past forms they had heard when they asked for clarification of the directions. 
Olivier:

What? Can you repeat? They went ...

Nina:

Okay. THEY THEY WENT EAST TO THE WOLVE

Olivier:

Okay.

Nina:

AND SOUTH PAST THE KIWI.

Félix:

What is that the kiwi?

In the intensive ESL program, students do a lot of choral repetition of well-known tongue twisters (e.g., Peter Piper; She sells sea shells). At this point in the program, the teacher felt the students had enough language to construct their own. The language support they were given consisted of the tongue twister models they were familiar with and their word lists/vocabulary banks, which included a range of verbs. The end goal of the task (which we did not observe) was going to be to recite their creation to the class, and then to write out, illustrate, and display the finished product in the hallway of the school. In some cases students chose to focus on a past event. When they did, they generated frequent contexts for using the past; they were constantly repeating aloud and adding to their text, as can be seen in the excerpt below.

Tongue Twister Excerpt 4

Maxime:

Charles:

Maxime:

Charles:

Maxime:

Charles:

Maxime:

Charles:

Maxime:

Later in the exchange:

Charles:

Maxime:

Charles:
A forest fire. Tried to save a French family in a forest from a forest fire.

Okay. What?

In fif-ty minutes. Good luck Franci- Frank.

Yes, okay.

And no not that. French family and flowers from a fire uh a forest fire.

What did you said?

And flower. Frank the firefighter tried to save a French family and flower from a forest fire in fifteen minutes

In uh what? In

In fifteen minutes.

He tried with uh with the water of a, we could say first, first he tried to with uh with the water of a fish bucal (French for bowl, but pronounced in English like buckle). Avec (French for with) a fish bowl Yes. 
Later in the exchange:

Charles:

I have Frank the funny fire fighter tried to save a French fam- a French family and flowers in a forest from a fire in fifteen minute with the water of the fish bowl, so he called the, the fire station for help.

Maxime: $\quad$ Yeah. He called the fire station for help.

The explanation for the frequent contexts for atelic verb types is that all four tasks offered opportunities to go beyond single utterances or a simple narration of main events (which often prioritizes telics, such as went, found, etc.) to include background information and perspectives (which involve more activities such as watched, waited, and statives, such as wanted, needed). Moreover, in writing their tongue twisters, the students were encouraged to be creative and use their resources (previously learned tongue twisters, workbooks, vocabulary banks, dictionaries).

\section{Discussion}

The oral interaction tasks we observed for the study were communicative, engaged the students, and also generated some focus on language in the form of student-initiated language-related episodes (which we report in a separate study). Our interest was in whether the tasks also provided contexts for students to stretch their interlanguage in terms of their use of two challenging forms: the simple past and the PDs his/her. Overall, across the 26 hours of recorded interaction, there were few contexts for talking about others (creating uses for his/her) or about events displaced in time (creating the need for past tense). Moreover, there was never a need to describe kin-different relationships, the situations that help learners consolidate the rule for the possessorgoverned choice of the correct PD in English. A small adjustment to the open interview about the weekend could have provided such a need by asking students to find out not only what their partners did, but with whom they did it. Then, in a posttask reporting phase, they would have had task-natural opportunities to say, for example, She played hockey with her brother, or Daniel went to the mall with his mother and his grandmother.

However, some of the tasks did provide quality contexts and opportunities for practice with the simple past, involving a range of verb types and inherent repetition of the forms. As Gatbonton and Segalowitz (2005) have proposed, inherent repetition of speech forms within tasks leads to automaticity and is important for learning. One key task feature that appeared to explain this finding was the inclusion of text-based modelling/language support as a stage within the task sequence-the sample questions to use for the weekend interviews, for example, or the recital of tongue twisters prior to the creation of the students' own versions for others to recite. This 
corresponds to the "pedagogical" phase proposed by Norris (2009) as a key component in task-based pedagogy in which language needed for the task is identified, reviewed, and/or practiced. The result is not necessarily taskessential language (Loschky \& Bley-Vroman, 1993), a situation difficult to create in oral production, as Loschky and Bley-Vroman (1993) and Garcia Mayo (2002) have pointed out, but possibly more task "likely," much in the way that recent work on priming endeavours to create the conditions for the use of key forms (Trofimovich \& McDonough, 2011). The importance of this phase was apparent in the Zoo Game task, in which the reading of the scripted clues provided students with multiple quality examples of the simple past as they focused on solving the missing animal problem. In analyzing this task, however, we realized that, unlike the tongue twister task, in which students moved from given language to their own language, the zoo task did not have a logical (and pedagogically appropriate) posttask in which students could create their own version of the zoo game for their classmates to play. Moreover, as this would have been the fourth in a sequence of tasks that involved the language of giving directions, we can hypothesize that repetition of the language of directions across the tasks would have led to some degree of automaticity. This in turn might have allowed students to focus on other language features in their creation of the game, including the simple past.

These observations on the task conditions facilitating practice of simple past and PDs (inherent repetition, language support/modelling, repetition of tasks with decreasing levels of language support) would be relevant to the use of other complex forms that may not arise frequently or in optimal learning conditions during "typical" communicative tasks (e.g., modals, passives, conditional, question formation). For learners to have the opportunity to participate in "pushed" output (self- and peer-generated reflection on new or partially acquired language), the tasks they engage in need to generate the need for the forms to be used in the first place.

\section{Conclusion}

The large corpus of learner interaction during typical classroom tasks created by the teacher for this study revealed a number of task types that have not previously received research attention, such as interviews, reaching consensus, giving directions, and making predictions. The study further allowed us to gain a better understanding of the language practice opportunities that arise in learner-learner interaction in an actual classroom, and to identify some of the task characteristics that provide more quality practice opportunities with challenging forms. This, in turn, allowed us to identify some task types that may merit further investigation in future pedagogical intervention studies designed to enhance the acquisition of different features of language. Of particular interest are short problem-solving tasks involving written clues 
or riddles that provide models of forms that are not yet productive in the students' interlanguage (like the Zoo Game). This could subsequently lead to the creation of a new riddle or set or clues, in which students would have the opportunity to push their interlanguage. We would also like to work with teachers to modify some of the existing tasks used to include more specific language goals and task phases that would enhance the acquisition potential of the tasks being used. One clear advantage of such collaboration is that the modifications would involve tasks already in use in language classrooms, greatly enhancing the pedagogical implications of the research.

\section{Notes}

1 The authors began with 100 studies published between 1980 and 2003, but only 14 met the inclusion criteria for the meta-analysis.

2 A notable recent exception to the laboratory trend is McDonough's (McDonough, 2011; McDonough \& Chaikitmongkol, 2010) investigations of the effectiveness of different collaborative priming activities on the elicitation of $w h$-questions during actual in-class peer interaction among Thai university EFL students.

3 While it is possible to rely on devices such as temporal adverbs to situate events in the past, a major developmental step involves going beyond the "basic variety" (Klein, 1995) to use the grammatical devices of a language to situate events in time and describe how the events unfold. 4 There were no contexts for their or its, and the three instances of our accounted for only $0.4 \%$ of the distribution of PDs, which disappeared when the numbers were rounded.

5 Some repetition of the same verbs within the corpus is to be expected, given the fact that it represents the language used by multiple pairs/groups doing the same task.

6 Four additional occurrences were "other" or uncodable.

7 Note that this was not an intended design feature of this task; however, it points to a distinct learning opportunity for students when authentic language is provided as part of a task.

\section{Acknowledgements}

We are grateful to the teacher and her students for welcoming us into their classroom and allowing us to observe and record their interactions. We also acknowledge the constructive suggestions from two anonymous reviewers as well as the quality of the collaboration provided by the excellent team of Concordia University research assistants who participated in the data collection, transcription, and coding: Katherine Ashmore, Fatma Bouhlal, Alexandra Demers, Victoria Dwight, Alexandra Imperiale, Jessica Prioletta, Stephanie McNaughton, and Tayebeh Shalmani. Funding for the project was provided through a team grant from the Quebec Ministry of Education (Fonds Québecois de la recherche sur la société et la culture).

\section{The Authors}

Laura Collins and Joanna White are associate professors in the Department of Education, Concordia University. In their teaching and research, they focus on maximizing the benefits of instruction in second language classrooms for learners of different ages in a variety of instructional contexts. They regularly present pedagogically relevant findings from their research to the teacher audience at the TESL Canada-affiliated SPEAQ (Société de perfectionnement de l'enseignement de l'anglais langue second au Québec) conference.

\section{References}

Bardovi-Harlig, K. (2000). Tense and aspect in second language acquisition: Form, meaning, and use. Oxford, UK: Blackwell. 
Bayley, R. (1996). Competing constraints on variation in the speech of adult Chinese learners of English. In R. Bayley \& D. R. Preston (Eds.), Second language acquisition and linguistic variation (pp. 97-120). Philadelphia, PA: John Benjamins.

Bell, P., Trofimovich, P., \& Collins, L. (in press). Kick the ball or kicked the ball? Perception of the past morpheme -ed by second language learners. Canadian Modern Language Review.

Cobb, T. (2000). The Compleat Lexical Tutor [Web site]. Retrieved from http://www.lextutor.ca

Collins, L. (2002). The roles of L1 influence and lexical aspect in the acquisition of temporal morphology. Language Learning, 52(1), 43-94.

Collins, L. (2004). The particulars on universals: A comparison of the acquisition of tense- aspect morphology among Japanese- and French-speaking learners of English. Canadian Modern Language Review, 61(2), 251-274.

Collins, L., Halter, R. H., Lightbown, P. M., \& Spada, N. (1999). Time and the distribution of time in second language instruction. TESOL Quarterly, 33(4), 655-680.

Collins, L., Trofimovich, P., White, J., Cardoso, W., \& Horst, M. (2009). Some input on the easy/ difficult grammar question: An empirical study. Modern Language Journal, 93(3), 336-353.

Collins, L., \& White, J. (2011). An intensive look at intensity and language learning. TESOL Quarterly, 45(1), 106-133.

Collins, L., White, J., Trofimovich, P., Cardoso, W., \& Horst, M. (2012). When comprehensible input is not comprehensive input: A multidimensional analysis of instructional input in intensive English as a foreign language. In C. Muñoz (Ed.), Intensive exposure experiences in second language learning (pp. 66-87). Bristol, UK: Multilingual Matters.

Ellis, R. (2009). Task-based language teaching: Sorting out the misunderstandings. International Journal of Applied Linguistics, 19(3), 221-246.

Ellis, R., \& Shintani, N. (2014). Exploring language pedagogy through second language acquisition research. New York, NY: Routledge.

Garcia Mayo, M. P. (2002). Interaction in advanced EFL pedagogy: A comparison of form-focused activities. International Journal of Educational Research, 37(3-4), 323-341.

Gatbonton, E., \& Segalowitz, N. (2005). Rethinking communicative language teaching: A focus on access to fluency. Canadian Modern Language Review, 61(3), 325-353.

Goad, H., White, L., \& Steele, J. (2003). Missing inflection in L2 acquisition: Defective syntax or L1-constrained prosodic representations? Canadian Journal of Linguistics, 48(3/4) 243-263.

Keck, C., Iberri-Shea, G., Tracy-Ventura, N., \& Wa-Mbaleka, S. (2006). Investigating the empirical link between task-based interaction and acquisition: A meta-analysis. In J. Norris \& L. Ortega (Eds.), Synthesizing research on language learning and teaching (pp. 91-131). Philadelphia, PA: John Benjamins.

Klein, W. (1995). The acquisition of English. In R. Dietrich, W. Klein, \& C. Noyau (Eds.), The acquisition of temporality in a second language (pp. 31-70). Amsterdam, The Netherlands: John Benjamins.

Lee, E. J. (2001). Interlanguage development by two Korean speakers of English with a focus on temporality. Language Learning, 51(4), 591-633.

Lightbown, P. M. (2012). Intensive L2 instruction in Canada: Why not immersion? In C. Muñoz (Ed.), Intensive exposure experiences in second language learning (pp. 25-44). Bristol, UK: Multilingual Matters.

Long, M. H. (1983). Does second language instruction make a difference? A review of research. TESOL Quarterly, 17(3), 359-382.

Long, M. H. (1996). The role of the linguistic environment in second language acquisition. In W. C. Ritchie \& T. K. Bhatia (Eds.), Handbook of second language acquisition (pp. 413-468). New York, NY: Academic Press.

Loschky, L., \& Bley-Vroman, R. (1993). Grammar and task-based methodology. In G. Crookes \& S. M. Gass (Eds.), Tasks and language learning: Integrating theory and practice (pp. 123-167). Clevedon, UK: Multilingual Matters.

Mackey, A. (1999). Input, interaction, and second language development: An empirical study of question formation in ESL. Studies in Second Language Acquisition, 21(4), 557-589. 
Mackey, A., \& Goo, J. (2007). Interaction research in SLA: A meta-analysis and research synthesis. In A. Mackey (Ed.), Conversational interaction in second language acquisition: A series of empirical studies (pp. 407-453). Oxford, UK: Oxford University Press.

McDonald, J. L., \& Roussel, C. C. (2010). Past tense grammaticality judgment and production in non-native and stressed native English speakers. Bilingualism: Language and Cognition, 13(4), 429-448.

McDonough, K. (2011). Eliciting wh-questions through collaborative syntactic priming activities during peer interaction. In P. Trofimovich \& K. McDonough (Eds.), Applying priming methods to L2 learning, teaching and research: Insights from psycholinguistics (pp. 131-151). Philadelphia, PA: John Benjamins.

McDonough, K., \& Chaikitmongkol, W. (2010). Collaborative syntactic priming activities and EFL learners' production of wh-questions. Canadian Modern Language Review, 66(6), 817-841.

Norris, J. M. (2009). Task-based teaching and testing. In M. H. Long \& C. J. Doughty (Eds.), The handbook of language teaching (pp. 578-594). Malden, MA: Wiley-Blackwell.

Philp, J., Adams, R., \& Iwashita, N. (2014). Peer interaction and second language learning. New York, NY: Routledge.

Pica, T. (1987). Second language acquisition, social interaction, and the classroom. Applied Linguistics, 8(1), 3-21.

Pica, T., Kang, H. S., \& Sauro, S. (2006). Information gap tasks: Their multiple roles and contributions to interaction research methodology. Studies in Second Language Acquisition, 28(2), 301-338.

Pinter, A. (2007). Some benefits of peer-peer interaction: 10-year-old children practicing with a communication task. Language Teaching Research, 11(2), 189-207.

Robinson, P. (2001). Task complexity, task difficulty, and task production: Exploring interactions in a componential framework. Applied Linguistics, 22(1), 27-57.

Rohde, A. (1996). The aspect hypothesis and the emergence of tense distinctions in naturalistic L2 acquisition. Linguistics, 34(5), 1115-1138.

Russell, J., \& Spada, N. (2006). The effectiveness of corrective feedback for the acquisition of L2 grammar: A meta-analysis of the research. In J. Norris \& L. Ortega (Eds.), Synthesizing research on language learning and teaching (pp. 133-164). Amsterdam, The Netherlands: John Benjamins.

Samuda, V., \& Bygate, M. (2008). Tasks in second language learning. New York, NY: Palgrave Macmillan.

Scrivener, J. (2011). Learning teaching: The essential guide to English language teaching. Oxford, UK: Macmillan.

Skehan, P., \& Foster, P. (1997). Task type and task processing conditions as influences on foreign language performance. Language Teaching Research, 1(3), 185-211.

Skehan, P., \& Foster, P. (2001). Cognition and tasks. In P. Robinson (Ed.), Cognition and second language instruction (pp. 183-205). Cambridge, UK: Cambridge University Press.

Storch, N., \& Aldosari, A. (2013). Pairing learners in pair-work activity. Language Teaching Research, 17(1), 31-48.

Swain, M. (1993). The output hypothesis: Just speaking and writing aren't enough. Canadian Modern Language Review, 50(1), 158-164.

Swain, M. (1995). Three functions of output in second language learning. In G. Cook \& B. Seidlhofer (Eds.), Principle and practice in applied linguistics: Studies in honour of $H$. G. Widdowson (pp. 125-144). Oxford, UK: Oxford University Press.

Swain, M., \& Lapkin, S. (2000). Task-based second language learning: The uses of the first language. Language Teaching Research, 4(3), 251-274.

Swain, M., \& Lapkin, S. (2001). Focus on form through collaborative dialogue: Exploring task effects. In M. Bygate, P. Skehan, \& M. Swain (Eds.), Researching pedagogic tasks: Second language learning, teaching, and testing (pp. 99-118). London, UK: Longman.

Trofimovich, P., \& McDonough, K. (2011). Applying priming methods to L2 learning, teaching and research: Insights from psycholinguistics. Philadelphia, PA: John Benjamins. 
White, J. (1998). Getting the learners' attention: A typographical input enhancement study. In C. Doughty \& J. Williams (Eds.), Focus on form in classroom second language acquisition (pp. 85-113). Cambridge, UK: Cambridge University Press.

White, J., \& Cardoso, W. (2012, July). When L1-based awareness can speed up the acquisition of L2 grammar. Paper presented at the 11th international conference of the Association for Language Awareness (ALA), Montreal, Quebec.

White, J., Munoz, C., \& Collins, L. (2007). The his/her challenge: Making progress in a "regular" L2 programme. Language Awareness, 16(4), 278-299.

White, J., \& Ranta, L. (2002). Examining the interface between metalinguistic task performance and oral production in a second language. Language Awareness, 11(4), 259-290.

Williams, J. (2001). Learner-generated attention to form. Language Learning, 51(s1), 303-346.

Wolfram, W. (1985). Variability in tense marking: A case for the obvious. Language Learning, 35(2), 229-253. 